\title{
Transcutaneous continuous carbon dioxide tension monitoring reduced incidence, degree and duration of hypercapnia during combined regional anaesthesia and monitored anaesthesia care in shoulder surgery patients
}

\author{
Werner Baulig • Marija Keselj • Barbara Baulig • \\ Sandra Guzzella $\cdot$ Alain Borgeat $\cdot$ José Aguirre
}

Received: 22 May 2014/Accepted: 7 October 2014/Published online: 14 October 2014

(C) Springer Science+Business Media New York 2014

\begin{abstract}
We studied the impact of transcutaneous continuous carbon dioxide tension $\left(\mathrm{PtcCO}_{2}\right)$ monitoring on ventilation and oxygenation during monitored anaesthesia care (MAC) in patients scheduled for shoulder surgery with continuous interscalene block. 50 patients were randomised either to the intervention (I-group) or the control (C-group) group. In both groups MAC was performed using target controlled infusion of propofol and remifentanil. MAC regimen was adapted to $\mathrm{PtcCO}_{2}$ values in the I-group, whereas the $\mathrm{C}$-group was blinded for these values. Primary outcome was the incidence, degree and duration of hypoventilation stages. In the I-group and the $\mathrm{C}$-group the mean $\pm \mathrm{SD}$ [range] of $\mathrm{PtcCO}_{2}$ and $\mathrm{PaCO}_{2}$ was $5.79 \pm$ 0.84 [4.37] and $5.44 \pm 0.59$ [2.78] $\mathrm{kPa}$, as well as $6.41 \pm$ 1.17 [6.29] and $6.01 \pm 0.96$ [7.15] kPa. Periods of $\mathrm{PtcCO}_{2} /$ $\mathrm{PaCO}_{2}>6.5 \mathrm{kPa}$ were $21.0 \pm 35.7 / 1.2 \pm 4.2 \mathrm{~min}$ in the I-group and 45.6 $\pm 40.0 / 18.6 \pm 26.8 \mathrm{~min}$ in the $\mathrm{C}$-group. Severe hypercapnia $\left(\mathrm{PtcCO}_{2}\right.$ and/or $\left.\mathrm{PaCO}_{2}>7.5 \mathrm{kPa}\right)$ was dected in $3 / 0$ patients of the I-group and in $10 / 3$ patients of
\end{abstract}

Werner Baulig and Marija Keselj have contributed equally to this work.

\footnotetext{
W. Baulig $(\square)$

Department of Anaesthesiology and Intensive Care Medicine, Klinik Im Park, Seestrasse 220, 8027 Zurich, Switzerland

e-mail: werner.baulig@hirslanden.ch

W. Baulig · M. Keselj · B. Baulig · S. Guzzella - A. Borgeat · J. Aguirre

Division of Anaesthesiology, Balgrist University Hospital,

Zurich, Switzerland

M. Keselj $(\bowtie) \cdot$ B. Baulig · S. Guzzella · A. Borgeat .

J. Aguirre

Institute of Anaesthesiology, University Hospital Zurich, Zurich,

Switzerland
}

the $\mathrm{C}$-group. $\mathrm{PtcCO}_{2}$ and $\mathrm{PaCO}_{2}$ showed a strong correlation $(\mathrm{r}=0.78)$, but only moderate agreement with a mean bias (LOA) of $-0.37(-1.69 ;+0.95) \mathrm{kPa}$ showing an overestimation of the $\mathrm{PaCO}_{2}$. Sensitivity and specificity of $\mathrm{PtcCO}_{2}$ to detect changes of $\mathrm{PaCO}_{2}$ was 0.94 and 0.56 , respectively. In no patient $\mathrm{SpO}_{2}$ or $\mathrm{SaO}_{2}$ values lower than $90 \%$ were measured. Despite a moderate agreement between $\mathrm{PaCO}_{2}$ and $\mathrm{PtcCO}_{2}$ the $\mathrm{PtcCO}_{2}$ monitoring significantly reduced incidence, degree and duration of hypercapnia in shoulder surgery patients with MAC.

Keywords $\mathrm{PtcCO}_{2}$ and $\mathrm{SpO}_{2}$ monitoring - MAC . Shoulder surgery $\cdot$ Ventilation

\section{Introduction}

Regional anaesthesia combined with mild to moderate sedation using monitored anaesthesia care (MAC) is commonly used in orthopaedic surgery [1]. MAC involves administration of drugs for anxiolytic, hypnotic, amnestic, and analgesic effect in order to achieve general anaesthesia, preserving the patients spontaneous breathing. Oxygenation of the spontaneous breathing patients is frequently supported by increasing the inspiratory oxygen supply and respiratory function is routinely monitored by pulse oximetry partial oxygen saturation $\left(\mathrm{SpO}_{2}\right)$. However, pulse oximetry is not sensitive for fast detection of ventilation disorders. Especially in shoulder surgery patients in beach chair position with a mild to moderate sedation, significant ventilatory impairment and subsequent decrease of oxygen saturation could occur. Adequate ventilation is best monitored by the arterial carbon dioxide tension $\left(\mathrm{PaCO}_{2}\right)$, which requires arterial cannulation for repeated blood gas analyses. This invasive, discontinuous and potentially complication-prone 
monitoring is used only if additional information like continuous blood pressure monitoring is needed. Next to the end-tidal carbon dioxide reading the transcutaneous continuous partial carbon dioxide $\left(\mathrm{PtcCO}_{2}\right)$ measurement represents a non-invasive alternative, which has been clinically used for more than 30 years [2]. In the last decade, combined assessment of $\mathrm{PtcCO}_{2}$ and $\mathrm{SpO}_{2}$ using a single ear-lobe clip sensor has been increasingly used in adult patients during non-invasive mechanical ventilation [3], transport of critically ill adults [4], bronchoscopy [5], sleep studies [6, 7] and pulmonary stress testing [8]. However, the findings of studies on neonates, infants and adults remain contradictory [4, 911]. Most recently, the revised V-Sign 2 sensor (V-Sign ${ }^{\mathrm{TM}} 2$ sensor, SenTec Digital Monitoring System; SenTec AG, Therwil, Switzerland) has become commercially available and its usefulness has been demonstrated during polysomnography-monitored sleep studies in 24 patients receiving non-invasive ventilation [12] and in patients after cardiac surgery [13]. The primary outcome of this study was to investigate the incidence and duration of significant states of hypoventilation and states of deoxygenation in patients scheduled for shoulder surgery in beach chair position with continuous interscalene block and MAC adapted or not to the $\mathrm{PtcCO}_{2}$ values. The second outcome was to demonstrate that significant states of hypoventilation and desaturation can be reduced by modifying the compilation of the sedative and analgesic drug concentration during surgery maintaining a calm, pain-free and cooperative patient.

\section{Methods}

This prospective, assessor-blinded study was approved by the Cantonal Ethics Committee Zurich, Switzerland (Registration Number: 2010-0170/4). After obtaining written informed consent fifty patients scheduled for elective, unilateral shoulder surgery were included. In all patients regional anaesthesia was combined with MAC to achieve mild to moderate sedation. Randomisation was performed the evening prior to surgery according to a computerised randomisation list allocating 25 patients to the intervention (I-group) and 25 patients to the control (C-group) group. Exclusion criteria were age $<18$ years; known clinically relevant cardiac, pulmonary or vascular shunts; too small ear-lobe for appropriate transcutaneous measurement; contraindications for placement of an interscalene catheter or arterial line and not sufficient german language skills. Mild to moderate sedation was defined according to Standards, Guidelines and Statements of the Amercian Society of Anesthesiologists [14] and was monitored using the modified Observer's Assessment of Alertnes/Sedation scale (OAAS) $[15,16]$ and the Bispectral index EEG (BIS). The OAAS score 4 (lethargic responses to name in normal tone) corresponded to mild and the OAAS score 3 (responds only after name is called loudly and/or repeatedly) to moderate sedation level. [1] According to the manufacturers depiction BIS values in the range of 89-80 and 79-70 were defined to correspond to mild and moderate sedation level, respectively.

Oral premedication of all patients consisted in midazolam $0.1 \mathrm{mg} / \mathrm{kg}$ body weight up to a maximum of $7.5 \mathrm{mg}$ 30 min prior to MAC induction. All patients received a standard monitoring (ECG, non-invasive blood pressure and pulseoximetry) and placement of an intravenous access in the induction area. A self-adhesive BIS ${ }^{\mathrm{TM}} 4$ Electrode Sensor (BIS) was placed on the forehead according to the manufacturer's recommendations. The radial artery was cannulated on the non-operated arm. Additionally, a V-Sign 2 sensor of the sentec device (SenTec Digital Monitor; SenTec AG; Therwil, Switzerland) was placed on the earlobe opposite to the surgical field and connected to the SenTec device. $\mathrm{PtcCO}_{2}, \mathrm{~V}$-Sign 2 sensor $\mathrm{SpO}_{2}$ (Vsign $\mathrm{SpO}_{2}$ ) and $\mathrm{V}$-Sign 2 sensor pulse rate (VsignPR) values displayed on the Sentec device were visible for the anaesthesiologist in the I-group, whereas in the C-group the anaesthesiologist was blinded. According to the institutional standards for shoulder surgery in beach chair position, an interscalene catheter with an initial bolus administration (30-40 ml ropivacaine $0.5 \%$ ) was placed. After block success was assessed, in all patients MAC was started to attain a mild or moderate sedation level of the spontaneous breathing patient. [17] The desired sedation level and analgesia for comfort during beach chair position was achieved using a combined target controlled infusion of propofol and remifentanil. After proper patient positioning and with the beginning of the sterile surgical field preparation the sedation with propofol $(0.5-0.8 \mu \mathrm{g} / \mathrm{ml}$ effect site concentration) and analgesia using remifentanil (0.5-0.8 ng/ml effect site concentration, target-controlled infusion pump, Graseby; SIMS Graseby Limited Watford, Herts, UK) was started. In both groups the target sedation level during surgery was an OAAS score of 4-3 to ensure a mild to moderate sedated but cooperative patient. Additionally, the $\mathrm{PtcCO}_{2}$ values in the I-group were kept in a range between 4.5 and $6.0 \mathrm{kPa}$. To maintain the $\mathrm{PtcCO}_{2}$ values in the I-group between 4.5 and $6.0 \mathrm{kPa}$ the anaesthesiologist varied the effect site concentrations of propofol and remifentanil. According to our experience, hyperventilation derived from incommodiousness due to the sitting position. Additionally, the patients were contacted and interviewed for possible pain or discomfort. First line treatment was the intravenous application of the peripherally acting analgesic paracetamol in a dose of $10-15 \mathrm{mg} / \mathrm{kg}$ body weight. Additionally, the effect site concentration of remifentanil was increased. Second line treatment included the intravenous application of the centrally acting $\alpha_{2}$ - 
adrenergic agonist clonidine. Clonidine $0.075 \mathrm{mg}$ was dissolved in $100 \mathrm{ml}$ sodium chloride $0.9 \%$ and infused over a period of $30 \mathrm{~min}$ to avoid cardiovascular complications. Increasing the propofol effect site concentration was the third line treatment. Hypoventilation states were treated by reducing the remifentanil effect site concentration first, and secondly reducing the propofol effect site concentration. Body temperature was maintained at $\geq 36.0{ }^{\circ} \mathrm{C}$ using a forced-air warming system $\left(3 \mathrm{M}^{\mathrm{TM}}\right.$ Bair Hugger $^{\mathrm{TM}}$ Temperature Management Unit 775, 3MHealthCare, UK).

All data generated by the V-Sign 2 sensor $\left(\mathrm{PtcCO}_{2}\right.$, $\mathrm{VsignSpO}_{2}$ and $\mathrm{VsignPR}$ ) were recorded continuously by an online computing system. The time points of the arterial samples and the results of the respective corresponding blood gas and blood oxygenation values were also collected in the online computing system. Moreover, these data, excluding the data of the $\mathrm{C}$-group, were recorded simultaneously in an offline protocol. The data of the $\mathrm{C}$-group produced online at the respective time points were documented offline at the end of the study protocol. Additional offline recordings at the time points of arterial blood sampling included BIS, OAAS, pulse rate (PR), systolic, diastolic and mean arterial presure (MAP), pulse oximetry saturation $\left(\mathrm{SpO}_{2}\right)$, inspired oxygen fraction $\left(\mathrm{FiO}_{2}\right)$ in $\mathrm{L} / \mathrm{min}$, arterial oxygen saturation $\left(\mathrm{SaO}_{2}\right)$, arterial partial oxygen pressure $\left(\mathrm{PaO}_{2}\right)$ and arterial partial carbon dioxide tension $\left(\mathrm{PaCO}_{2}\right)$. Blood samples were taken before placement of the interscalene catheter (1), after starting MAC (2), every $15 \mathrm{~min}$ during surgery until the end of surgery (3-14). Additionally, the cumulative doses of propofol $(\mathrm{mg})$ and remifentanil $(\mu \mathrm{g})$, clonidine $(\mu \mathrm{g})$, paracetamol (mg), epinephrine ( $\mathrm{mg}$ ) and the number of interventions for ventilation support were recorded.

$\mathrm{PaCO}_{2}$ was measured at a standard temperature of $37{ }^{\circ} \mathrm{C}$ and $\mathrm{SaO}_{2}$ was determined by multi-wavelength pulse oximetry (ABL 800, Radiometer Medical A/S Akandevej 21 DK-2700 Bronshoj, Denmark). Prior to the study start and 2, 4 and $12 \mathrm{~h}$ after removal of the V-Sign 2 sensor from the earlobe peripheral skin perfusion $[\mathrm{I}=$ warm and dry, $\mathrm{II}=\mathrm{cool}$, and III $=$ cold $]$ and skin status $[0=$ no reddening, $1=$ slight reddening, $2=$ reddening, $3=$ intensive reddening, and $4=$ blister] were assessed and documented.

After transfer to the post anaesthesia care unit (PACU) the following events were assessed: the incidence of respiratory depression, postoperative nausea and vomiting (PONV), the cumulative volume of crystalloid and colloid fluids, the cumulative doses of morphine, the time of discharge from the PACU to the ward, the pain level according to the Visual Analogue Scale $(\mathrm{VAS} /$, for $0=$ no pain; $100=$ worst imaginable pain) and the Aldrete Score [18]. Discharge criteria were VAS $\leq 30$ and Aldrete score $\geq 9$.
Hypercarbia as result of hypoventilation was defined as a value of $\mathrm{PtcCO}_{2} \geq 6.0 \mathrm{kPa}$ ( $>2 \mathrm{~min}$ ) and classified as mild $\left(\mathrm{PtcCO}_{2} \geq 6.0<6.5\right)$, moderate $\left(\mathrm{PtcCO}_{2} \geq 6.5\right.$ $<7.5)$ and severe $\left(\mathrm{PtcCO}_{2} \geq 7.5\right)$. Respiratory depression was defined as a persistant $(>2 \mathrm{~min})$ decrease in $\mathrm{SpO}_{2}$ below $90 \%$, or a sustained ( $>2 \mathrm{~min}$ ) increase in $\mathrm{PtcCO}_{2}$ above $7.0 \mathrm{kPa}$, or the need for active ventilatory support.

\subsection{Statistics}

The use of a paired $t$ test power calculation revealed a sample size of 42 patients ( 21 patients in each group) to achieve an $80 \%$ power to detect a mean difference of $0.6 \mathrm{kPa}$ (with $\alpha=0.05$ ) between the two groups with an estimated standard deviation (SD) of $0.7 \mathrm{kPa}$. The mean difference was determined based on clinical experience and previous studies with the used device. [13] This estimation hypothesised an uniform distribution of the actual data. The sample size calculation was performed with the StatsDirect Statistical Software Version 2.8.0 2013 (StatsDirect Ltd, Altrincham, UK). Continuous variables are presented as mean \pm SD. Normality of distribution was assessed with the Chapiro-Wilk test. Paired t-test or as appropriate the Mann-Whitney U-test were used to test continuous variables on differences. Categorical variables were tested for differences with the Pearson's Chi-square-test or the Fisher's exact test as appropriate. Bland-Altman analysis was performed for determination the agreement of $\mathrm{PaCO}_{2}$ and $\mathrm{PtcCO}_{2}$; PR and Vsign-PR and $\mathrm{SaO}_{2}$ and Vsign-SpO 2 . [19] BIS, OAAS, $\mathrm{PtcCO}_{2}, \mathrm{PaCO}_{2}, \mathrm{SaO}_{2}$, Vsign-SpO2, Vsign-PR and MAP were compared across time intervals using repeated measures of variance (ANOVA) and paired t-test. A $p$ value $<0.05$ was considered significant.

\section{Results}

Fifty patients were included in the study. No significant difference was found between groups regarding patient characteristics, surgical procedure, surgery and sedation time (Table 1). Propofol, remifentanil and clonidine consumption were not significantly different between groups, although a trend towards increased remifentanil and decreased propofol doses was shown in the I-group compared to the C-group (Table 2). Paracetamol doses were significantly higher $(p=0.007)$ in the I-group (Table 2$)$. During the process the mean \pm SD of the BIS and of the OAAS scale were similar in both groups (Table 3; Fig. 1a, b). No colloid fluid, vasoactive drugs or morphine were applied in both groups. No patient suffered from PONV or needed breathing or ventilatory support during and after surgery. Time of discharge from the PACU and crystalloid fluid consumption were not significantly different between 
Table 1 Patient and procedural characteristics; values are expressed as mean $\pm \mathrm{SD}$ or numbers

\begin{tabular}{llll}
\hline & $\begin{array}{l}\text { Intervention } \\
\text { group }\end{array}$ & $\begin{array}{l}\text { Control } \\
\text { group }\end{array}$ & $p$ value \\
\hline No. of patients & 25 & 25 & \\
Age (year) & $45.2 \pm 17$ & $43.6 \pm 14.9$ & 0.738 \\
Male/female & $17 / 8$ & $20 / 5$ & 0.344 \\
BMI (kg/m ${ }^{2}$ ) & $25.0 \pm 4.1$ & $25.3 \pm 4.4$ & 0.757 \\
ASA (I/II/III) & $12 / 13 / 0$ & $15 / 9 / 1$ & 0.608 \\
Type of surgery & & & \\
Shoulder arthroscopic surgery & 24 & 23 & \\
Removal osteosynthesis & 1 & 1 & \\
Re-osteosynthesis & 0 & 1 & \\
MAC time (min) & $89.0 \pm 38$ & $85.8 \pm 31.4$ & 0.747 \\
Surgery time (min) & $80.8 \pm 34.7$ & $70.4 \pm 26.6$ & 0.240 \\
Time of discharge from the & $25.5 \pm 6.4$ & $30.6 \pm 12.2$ & 0.874 \\
PACU & & & \\
\hline
\end{tabular}

BMI body mass index, $A S A$ Physical status classification system of the American Society of Anesthesiologists, MAC monitored anaesthesia care, $P A C U$ post anaesthesia care unit

groups (Tables 1 and 2). Pain intensity was lower and the mean Aldrete score at discharge was higher but without statistical significance in the I-group compared to the C-group (Table 2).

In the I-group and the $\mathrm{C}$-group the mean $\pm \mathrm{SD}$ [range] of $\mathrm{PtcCO}_{2}$ and $\mathrm{PaCO}_{2}$ was $5.79 \pm 0.84$ [4.37] and $5.44 \pm 0.59$ [2.78] kPa, as well as $6.41 \pm 1.17$ [6.29] and $6.01 \pm 0.96[7.15] \mathrm{kPa}$; and for $\mathrm{VsignSpO}_{2}$ and $\mathrm{SaO}_{2}$ $97.2 \pm 2.4[10]$ and $97.3 \pm 1.9 \quad[7.2]$, as well as $97.8 \pm 1.8 \quad[8]$ and $98.4 \pm 1.4 \quad[6.1]$, respectively
(Table 3). Table 2 presents the significantly longer duration of hypercapnia in the $\mathrm{C}$-group compared to the I-group. $\mathrm{PtcCO}_{2} / \mathrm{PaCO}_{2}>6.0 \mathrm{kPa}$ was detected in $15 / 10$ patients of the I-group and in 22/18 of the C-group. Severe hypercapnia $\left(\mathrm{PtcCO}_{2} / \mathrm{PaCO}_{2}>7.5 \mathrm{kPa}\right)$ was detected in $3 / 0$ patients of the I-group and in $10 / 3$ patients of the C-group. No hypercapnia $\left(\mathrm{PtcCO}_{2} / \mathrm{PaCO}_{2}<6.0 \mathrm{kPa}\right)$ was found in $10 / 15$ patients $(40 / 60 \%$ ) of the I-group and in $3 / 7$ patients $(12 / 28 \%)$ in the $\mathrm{C}$-group. In both groups $\mathrm{PtcCO}_{2}$ and $\mathrm{PaCO}_{2}$ increased during the course (Fig. 2a, b).

In no patient $\mathrm{SpO}_{2}$ or $\mathrm{SaO}_{2}$ values less than $90 \%$ were measured. $\mathrm{FiO}_{2}$ supply during the process was not different between groups. The mean $\pm \mathrm{SD} \mathrm{PaO}_{2}$ in the I-group and the C-group was $17.4 \pm 6.8$ and $20.1 \pm 6.9 \mathrm{kPa}$ $(p=0.003)$, respectively (Table 3$)$. The time course of the $\mathrm{PaO}_{2}$ in both groups showed, that the statistically significant differences were found during the time points 1 (before placement the catheter), 2 (immediately after starting MAC) and 3 (15 min after starting MAC) (Fig. 2c).

For Bland-Altman analysis 233 data pairs of $\mathrm{PtcCO}_{2}$ and $\mathrm{PaCO}_{2}$, and for $\mathrm{V}$-Sign $\mathrm{SpO}_{2}$ and $\mathrm{SaO}_{2}$ were available. $\mathrm{PtcCO}_{2}$ and $\mathrm{PaCO}_{2}$ showed a strong correlation $(\mathrm{r}=0.78)$, but the agreement was only moderate with a mean bias (LOA) of $-0.37(-1.69 ;+0.95) \mathrm{kPa}$ showing an overestimation the $\mathrm{PaCO}_{2}$ (Table 4; Fig. 3a, b). Sensitivity and specificity of $\mathrm{PtcCO}_{2}$ to detect changes of $\mathrm{PaCO}_{2}$ were 0.94 and 0.56 , respectively. $\mathrm{VsignSpO}$ and $\mathrm{SaO}_{2}$ were also strong correlated $(\mathrm{r}=0.71)$. Bland-Altman analysis showed a good agreement with a mean bias (LOA) of +1.2 $(-0.3 ;+2.7) \%$ resulting in a slight underestimation the $\mathrm{SaO}_{2}$ (Table 4). The strongest correlation $(\mathrm{r}=0.95)$ showed V-sign PR with the electrocardiographic measured

Table 2 Results of procedural data, values are expressed as mean \pm SD [range] or as mean \pm SD (median [range])

\begin{tabular}{|c|c|c|c|}
\hline & Intervention group & Control group & $p$ \\
\hline Midazolam (mg/kg) & $0.105 \pm 0.024[0.085]$ & $0.097 \pm 0.019[0.061]$ & 0.178 \\
\hline Propofol ( $\mu \mathrm{g} / \mathrm{kg} / \mathrm{min})$ & $48.8 \pm 12.6[47]$ & $52.5 \pm 22.8[90]$ & 0.474 \\
\hline Remifentanil (ng/kg/min) & $60.2 \pm 42.3[199]$ & $48.0 \pm 35.0[172]$ & 0.273 \\
\hline Paracetamol (mg/kg) & $12.7 \pm 4.8[20.0]$ & $8.0 \pm 7.0[18.2]$ & 0.007 \\
\hline Clonidine $(\mu \mathrm{g} / \mathrm{kg})$ & $1.9 \pm 0.7[3.0]$ & $1.7 \pm 1.0[4.8]$ & 0.509 \\
\hline Crystalloid (ml) & $864 \pm 218[900]$ & $929 \pm 255[1,300]$ & 0.309 \\
\hline VAS & $16 \pm 7[20]$ & $20 \pm 8[20]$ & 0.070 \\
\hline Aldrete score at discharge & $9.9 \pm 0.3[1]$ & $9.7 \pm 0.5[1]$ & 0.091 \\
\hline $\mathrm{PtcCO}_{2}>6.0(\mathrm{~min})$ & $42.4 \pm 47.4(30[180])^{\mathrm{a}}$ & $63.6 \pm 40.2(60[165])^{\mathrm{b}}$ & 0.067 \\
\hline $\mathrm{PtcCO}_{2}>6.5(\mathrm{~min})$ & $21.0 \pm 35.7(0[150])^{\mathrm{c}}$ & $45.6 \pm 40.0(45[165])^{\mathrm{d}}$ & 0.026 \\
\hline $\mathrm{PaCO}_{2}>6.0(\mathrm{~min})$ & $9.6 \pm 20.3(0[90])^{\mathrm{e}}$ & $37.8 \pm 34.4(30[105])^{\mathrm{f}}$ & 0.001 \\
\hline $\mathrm{PaCO}_{2}>6.5(\mathrm{~min})$ & $1.2 \pm 4.2(0[15])^{\mathrm{g}}$ & $18.6 \pm 26.8(15[105])^{\mathrm{h}}$ & 0.002 \\
\hline
\end{tabular}

VAS visual analog scale, Aldrete Aldrete postanaesthetic recovery score, $\mathrm{PtcCO}_{2}>6.0$ duration of $\mathrm{PtcCO}_{2}$ values $>6.0 \mathrm{kPa}, \mathrm{PtcCO} 2>6.5$ duration of $\mathrm{PtcCO}_{2}$ values $>6.5 \mathrm{kPa}, \mathrm{PaCO}_{2}>6.0$ duration of $\mathrm{PaCO}_{2}$ values $>6.0 \mathrm{kPa}, \mathrm{PaCO}_{2}>6.5$ duration of $\mathrm{PaCO} \mathrm{O}_{2}$ values $>6.5 \mathrm{kPa}$, $n$ number of patients

${ }^{\mathrm{a}} \mathrm{n}=16 ;{ }^{\mathrm{b}} \mathrm{n}=21 ;{ }^{\mathrm{c}} \mathrm{n}=11 ;{ }^{\mathrm{d}} \mathrm{n}=17 ;{ }^{\mathrm{e}} \mathrm{n}=10 ;{ }^{\mathrm{f}} \mathrm{n}=18 ;{ }^{\mathrm{g}} \mathrm{n}=3 ;{ }^{\mathrm{h}} \mathrm{n}=13$ 
Table 3 Results of continuous data, values are expressed as mean \pm SD [range]

\begin{tabular}{lccr}
\hline & Intervention group & Control group & \multicolumn{1}{c}{$p$} \\
\hline BIS & $80.1 \pm 10.6[53]$ & $81.0 \pm 11.4[48]$ & 0.687 \\
$\mathrm{OAAS}$ & $4.2 \pm 0.5[3]$ & $4.2 \pm 0.5[2]$ & 0.543 \\
$\mathrm{PaO}_{2}(\mathrm{kPa})$ & $17.4 \pm 6.8[37.3]$ & $20.1 \pm 6.9[36.6]$ & 0.003 \\
$\mathrm{PaCO}_{2}(\mathrm{kPa})$ & $5.44 \pm 0.59[2.78]$ & $6.01 \pm 0.96[7.15]$ & $<0.001$ \\
$\mathrm{PtcCO}_{2}(\mathrm{kPa})$ & $5.79 \pm 0.84[4.37]$ & $6.41 \pm 1.17[6.29]$ & $<0.001$ \\
$\mathrm{SaO}_{2}(\%)$ & $97.3 \pm 1.9[7.2]$ & $98.4 \pm 1.4[6.1]$ & 0.001 \\
$\mathrm{SpO}_{2}(\%)$ & $96.5 \pm 2.3[10]$ & $97.3 \pm 1.9[9]$ & 0.009 \\
$\mathrm{VsignSpO}_{2}(\%)$ & $97.2 \pm 2.4[12]$ & $97.8 \pm 1.8[8]$ & 0.098 \\
$\mathrm{PR}_{(\mathrm{bpm})}$ & $71.1 \pm 14[61]$ & $64.0 \pm 10.7[42]$ & $<0.001$ \\
VsignPR (bpm) & $71.7 \pm 13[56]$ & $64.4 \pm 10.4[40]$ & $<0.001$ \\
MAP (mmHg) & $81.4 \pm 15.5[75]$ & $80.4 \pm 17.2[81]$ & 0.170 \\
\hline BIS Bispectal & &
\end{tabular}

BIS Bispectral Index Electroencephalograpy, expressed as dimensionless count, OAAS Observer's Assessment of Alertness and Sedation Scale, $\mathrm{PaO}_{2}$ partial arterial oxygen tension, $\mathrm{SaO}_{2}$ arterial oxygen saturation, $\mathrm{SpO}_{2}$ oxygen saturation, VsignSpO $\mathrm{O}_{2}$ oxygen saturation detected by the V-Sign ${ }^{\mathrm{TM}} 2$ sensor, $P R$ pulse rate, VsignPR pulse rate detected by the $\mathrm{V}-\mathrm{Sign}^{\mathrm{TM}} 2$ sensor, $\mathrm{PaCO}_{2}$ partial arterial carbon dioxide tension, $\mathrm{PtcCO}_{2}$ transcutaneous continuous partial carbon dioxide tension detected by the $\mathrm{V}-\mathrm{Sign}^{\mathrm{TM}} 2$ sensor, MAP mean arterial pressure

PR, but the agreement was only moderate (Table 4). In forty-five of 50 patients the detection of the Vsign 2 sensor was again briefly disturbed by electro cautery ( 68 episodes), by mechanical compression of the sensor (7 episodes) and by air lock on the sensor membrane (27 episodes). No patient developed disorders of the peripheral skin perfusion or skin damage on the earlobes after the V-Sign 2 sensor was removed.

\section{Discussion}

The main findings of this study were (1) no significant disturbances of oxygenation were found in both groups, (2) $\mathrm{PtcCO}_{2}$ detected significant states of hypoventilation, (3) the incidence, degree and length of hypoventilation episodes were significantly reduced in the $\mathrm{PtcCO}_{2}$ monitored group, and (4) the agreement of $\mathrm{PtcCO}_{2}$ and $\mathrm{PaCO}_{2}$ was moderate with a overestimation of the $\mathrm{PaCO}_{2}$, but the sensitivity of $\mathrm{PtcCO}_{2}$ to detect changes of $\mathrm{PaCO}_{2}$ was high.

Recently, De Oliveira et al. [16] compared transcutaneous and nasal end-tidal carbon dioxide measurements against $\mathrm{PaCO}_{2}$ in deep sedated, spontaneous breathing patients undergoing ambulatory gynaecological hysteroscopy. They reported significant hypercapnic states in the patients during the procedure and demonstrated better agreement of $\mathrm{PtcCO}_{2}$ with $\mathrm{PaCO}_{2}$ compared to end-tidal measured $\mathrm{CO}_{2}$. In their study in 8 of 12 Patients with $\mathrm{PaCO}_{2}>6.65 \mathrm{kPa}$ the $\mathrm{PtcCO}_{2}$ agreed and $\mathrm{PtcCO}_{2}$ showed
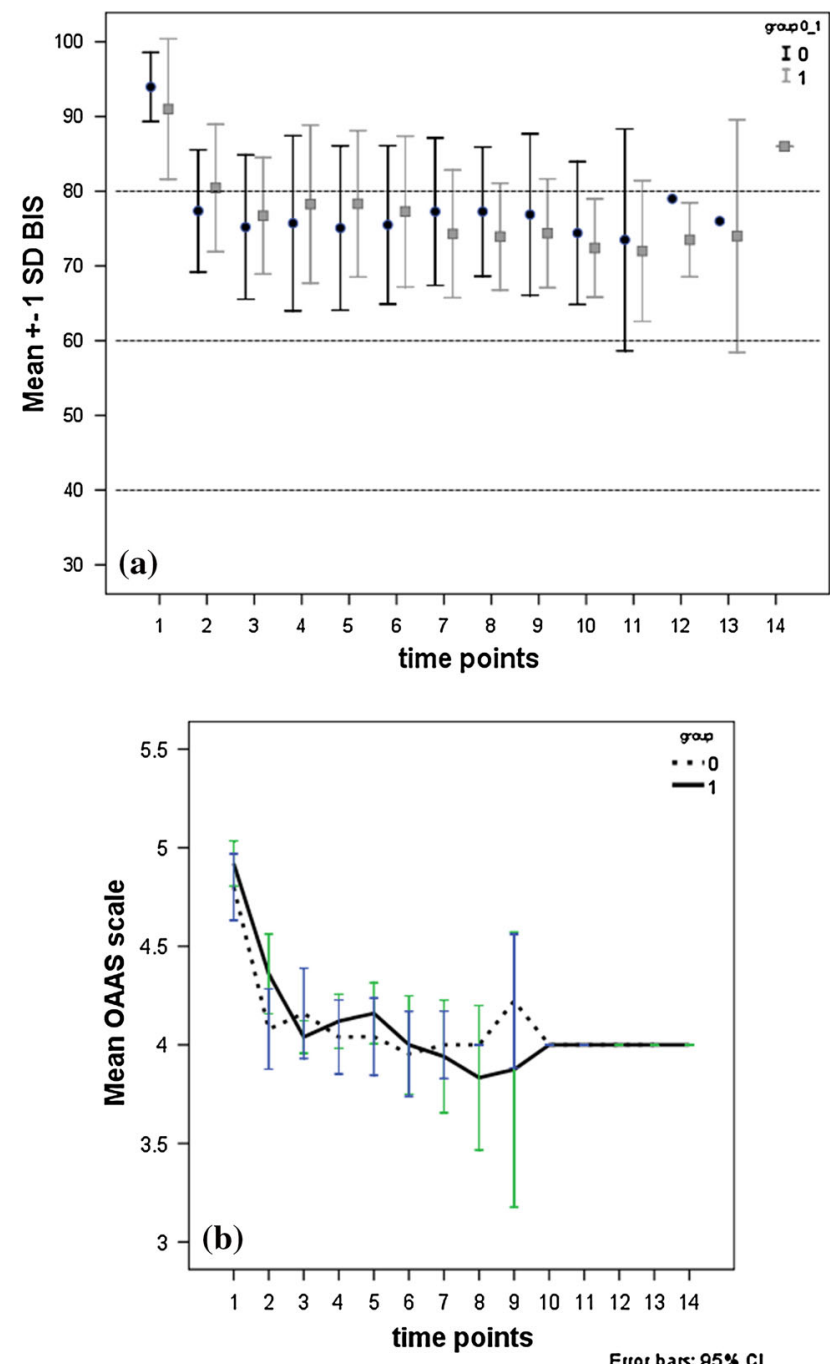

Fig. 1 a Bispectral Index EEG (BIS) and b Observer's Assessment of Alertness/Sedation scale (OAAS) changes during the course of the procedure. Data are presented as mean and $95 \%$ Confidence interval (error bar $95 \%$ CI). Definitions Time points are: before placement of the intersclalene catheter (1), after starting MAC (2), every $15 \mathrm{~min}$ during surgery until the end of surgery (3-14); group 0, control group; group 1, intervention group. By the time point 11 twenty-one and twenty-three operations were competed in the I-group and the C-group, respectively. Statistical analysis of the data at the remaining time points was omitted because of insufficient amount of data

a slight overestimation of the $\mathrm{PaCO}_{2}$ with a mean bias of $0.23 \mathrm{kPa}$. In the current investigation episodes of hypercapnia were detected in 28 patients with the $\mathrm{paCO}_{2}$ and in 37 patients with the $\mathrm{PtcCO}_{2}$. Most patients suffered mild to moderate hypercapnia. Severe hypercapnia was detected in 13 of these patients with the $\mathrm{PtcCO}_{2}$ but only in three patients with the $\mathrm{PaCO}_{2}$. These findings suggest that $\mathrm{PtcCO}_{2}$ considerably over-estimated the $\mathrm{PaCO}_{2}$, resulting in displaying false high values. The episodes of hypercapnia were detected in both groups. However, incidence, degree and duration of hypercapnia measured by $\mathrm{PaCO}_{2}$ 

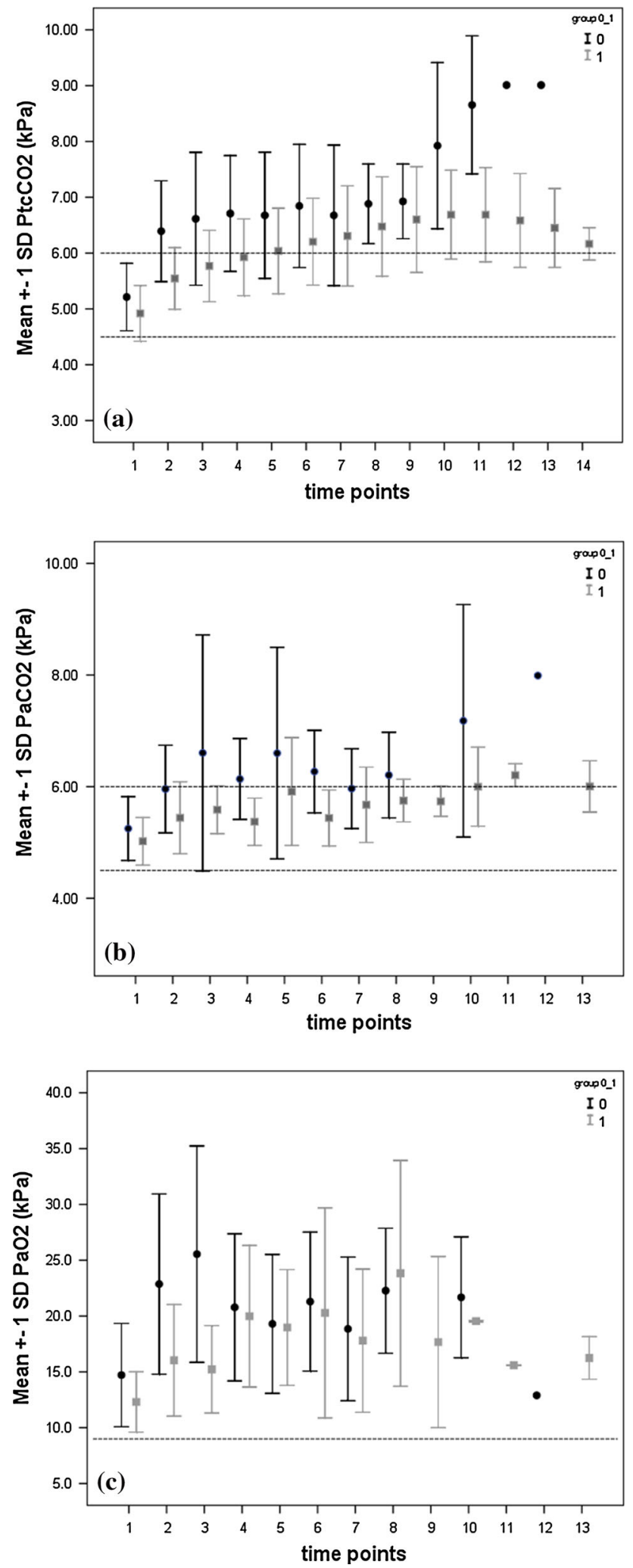

and $\mathrm{PtcCO}_{2}$ were significantly reduced in the I-group compared to the control group. Importantly, in both groups neither $\mathrm{SpO}_{2}$ measured with the V-Sign 2 sensor nor $\mathrm{SaO}_{2}$
4 Fig. 2 a $\mathrm{PtcCO}_{2}$, b $\mathrm{PaCO}_{2}$ and $\mathbf{c} \mathrm{PaO}_{2}$ changes of the C-group (0) and the I-group (1) during the course of the procedure. Data are presented as mean \pm SD. Definitions Time points are: before placement of the intersclalene catheter (1), after starting MAC (2), every 15 min during surgery until the end of surgery (3-14); C-group, control group; I-group, intervention group. By the time point 11 twenty-one and twenty-three operations were competed in the I-group and the C-group, respectively. Statistical analysis of the data at the remaining time points was omitted because of insufficient amount of data

Table 4 Correlation and agreement of the $\mathrm{SaO}_{2}$ and $\mathrm{VsignSpO}_{2}, \mathrm{PR}$ and VsignPR, and $\mathrm{PaCO}_{2}$ and $\mathrm{PtcCO}_{2}$

\begin{tabular}{|c|c|c|c|c|}
\hline & $\mathrm{n}$ & $\mathrm{r}$ & Mean bias & LOA \\
\hline $\mathrm{SaO}_{2}-\mathrm{VsignSpO}_{2}(\%)$ & 233 & 0.71 & +1.2 & $-0.3 /+2.7$ \\
\hline PR-VsignPR (bpm) & 390 & 0.95 & -0.2 & $-8.2 / 7.8$ \\
\hline $\mathrm{PaCO}_{2}-\mathrm{PtcCO}_{2}(\mathrm{kPa})$ & 233 & 0.78 & -0.37 & $-1.69 /+0.95$ \\
\hline
\end{tabular}

Mean bias mean difference between two methods of measurement, $L O A$ limits of agreement $( \pm 2 \mathrm{SD}$ of mean bias $=95 \%$ confidence interval), $\mathrm{SaO}_{2}-\mathrm{VsignSpO}_{2}$ difference between arterial oxygen saturation value and oxygen saturation detected by the $\mathrm{V}-\mathrm{Sign}^{\mathrm{TM}} 2$ sensor, $P R$-VsignPR difference between pulse rate value of the ECG and pulse rate detected by the $\mathrm{V}-\mathrm{Sign}^{\mathrm{TM}} 2$ sensor, $\mathrm{PaCO}_{2}-\mathrm{PtcCO}_{2}$ difference between partial arterial carbon dioxide tension value and corresponding transcutaneous continuous carbon dioxide value detected by the V-Sign ${ }^{\mathrm{TM}} 2$ sensor

showed values below $90 \%$. This result is mainly explained by the routine administration of oxygen during the MAC procedure, by the patient population included and the only mild to moderate sedation of the patients. Combined $\mathrm{PtcCO}_{2}$ and $\mathrm{SpO}_{2}$ measurement has been successfully used for continuous surveillance of spontaneous breathing patients after major abdominal surgery undergoing different postoperative pain treatments. In twenty-eight ASA I and II patients after elective major laparatomy, Kopka et al. [20] reported significant hypoventilation states in the patient-controlled analgesia group, whereas in the patients of the epidural anaesthesia group no hypoventilation states were observed. Similar results were found by McCormack et al. [21]. After major colorectal surgery $\mathrm{PtcCO}_{2}$ values were significantly elevated in the patient controlled analgesia group compared to patients receiving epidural analgesia monitored for $24 \mathrm{~h}$. As in the current investigation, in both studies no significant oxygenation disturbances measured by $\mathrm{SpO}_{2}$ were found in any patients. However, in the I-group of this investigation $\mathrm{PaO}_{2}, \mathrm{SaO}_{2}$ and $\mathrm{SpO}_{2}$ were statistically significant but not clinically relevant reduced compared to the C-group. Interestingly, these significant reduced oxygenation parameters were only found during the period between placement of the interscalene catheter and the 15 min sampling time point of surgery after starting MAC. In the further course of MAC no significant differences in $\mathrm{PaO}_{2}, \mathrm{SaO}_{2}$ and $\mathrm{SpO}_{2}$ were found between the groups. This observation cannot be explained with the 

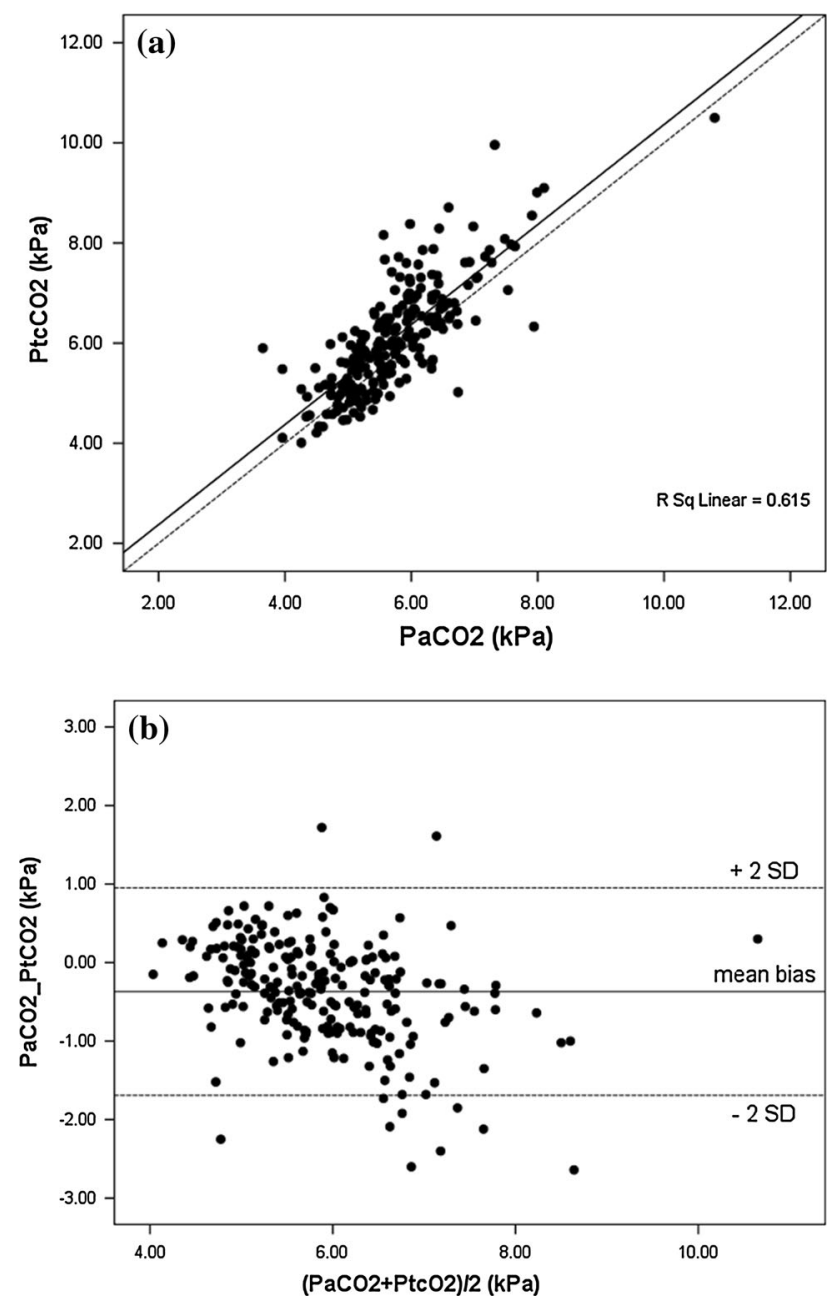

Fig. 3 a Linear correlation and $\mathrm{b}$ agreement of $\mathrm{PaCO}_{2}$ and $\mathrm{PtcCO}_{2}$ using the Bland-Altman analysis with $\mathrm{r}$ of $0.78\left(\mathrm{r}^{2}=0.615\right)$ and a mean bias and LOA of -0.37 and $-1.69 /+0.95 \mathrm{kPa}$. Definition a dashed line represents line of identity; b LOA Limits of agreement $(2 \mathrm{SD}=95 \% \mathrm{CI})$

only smooth and not significant modification of the MAC during the procedure. The application of less cumulative doses of propofol and higher cumulative doses of remifentanil in the I-group compared to the C-group was not significantly different and showed only a trend. Post hoc analysis of the applied blood concentrations of propofol $(\mu \mathrm{g} / \mathrm{ml})$ and of remifentanil $(\mathrm{ng} / \mathrm{ml})$ during the different time points of blood sampling have shown that no statistical significant difference was found between the blood concentrations of propofol and remifentanil between both groups at all time points (data not shown). In particular at the interesting time points the propofol blood plasma concentrations showed only a trend to be lower in the I-group compared to the C-group, whereas the remifentanil blood concentrations were similar in both groups. A possible reason for these findings might be a higher rate of possible recurrent laryngeal nerve palsy resulting in a diaphragmatic high level on the site of catheter placement. However, no chest X-ray was performed to assess this hypothesis due to the uneventful post-operative recovery.

Though, this smooth modification seemed to have significant impact on the ventilation state of the patients. $\mathrm{PtcCO}_{2}$ and $\mathrm{PaCO}_{2}$ values were significantly higher and the duration of the hypercapnic episodes were significantly longer in the C-group compared to the I-group. Whereas hypercapnia occurred in about two-thirds of patients in the $\mathrm{C}$-group, monitoring the $\mathrm{PtcCO}_{2}$ led to a reduction the incidence of hypercapnia to one-third of the patients in the I-group. The trend to have used higher doses of analgesics and reduced doses of hypnotics during MAC in the I-group is supported by the significant higher dose of paracetamol in the I-group compared to C-group. The beach chair position is an uncomfortable and often painful patient positioning and sufficient analgesia during the process is necessary. Therefore it may be assumed that progressive increasing carbon dioxide values, which were only visible for the anaesthesiologist in the I-group, led to the decision rather carefully to increase the remifentanil dose supported by the significant raised use of non-opiod analgesics accompanied by a concomitant reduction of the propofol dose. However, during the surgery no significant differences in the sedation level, measured with the OAAS and the BIS, were observed in both groups. Interestingly, the postoperative detected VAS values were significantly lower in the I-group compared to the C-group and the Aldrete Score showed a trend to by higher in the I-group.

Although $\mathrm{PtcCO}_{2}$ showed a strong correlation with $\mathrm{PaCO}_{2}$ and the sensitivity of $\mathrm{PtcCO}_{2}$ to detect a rise of $\mathrm{PaCO}_{2}$ was high, the agreement of $\mathrm{PtcCO}_{2}$ and $\mathrm{PaCO}_{2}$ in this study with spontaneous breathing patients was only moderate with a mean overestimation the $\mathrm{PaCO}_{2}$ of $0.39 \mathrm{kPa}$ and limits of agreement of -1.69 and $+0.95 \mathrm{kPa}$. In contrast to these results a good agreement of $\mathrm{PtcCO}_{2}$ and $\mathrm{PaCO}_{2}$ with a drift corrected mean bias and LOA of $+0.13 \mathrm{kPa}$ and $-0.63 /+0.89 \mathrm{kPa}$ was reported in 24 patients who required noctural non-invasive ventilation [12], in patients after cardiac surgery [13] and in patients scheduled for lung function testing because of ventilator disturbances or the necessity of non-invasive ventilation [22]. Additionally, in spontaneously breathing deep sedated patients undergoing ambulatory gynaecological hysteroscopy [16] and in non-intubated dyspnoic patients in an emergency department good agreement of $\mathrm{PaCO}_{2}$ and $\mathrm{PtcCO}_{2}$ has also been reported [23]. Contrary to our results, in both previous studies with spontaneous breathing patients no repeated measurements were calculated. Using the previous sensor technique of the Sentec device, Fanelli et al. [24] reported an only moderate mean bias and wide limits of agreement of repeatedly measured $\mathrm{PaCO}_{2}$ and $\mathrm{PtcCO}_{2}$ in spontaneously breathing, non-intubated patients 
in the early postoperative period after major abdominal, vascular, or thoracic surgery. They hypothesised that $\mathrm{PtcCO}_{2}$ could be partially uncoupled from $\mathrm{PaCO}_{2}$ during spontaneous, irregular breathing patterns, because failed re-equilibration of the central compartment with the carbon dioxide buffer systems and possible interindividual differences in terms of $\mathrm{CO}_{2}$ buffering. Post hoc analysis the agreement of $\mathrm{PaCO}_{2}$ and $\mathrm{PtcCO}_{2}$ at each sampling time point of this study clearly demonstrated a good agreement with a mean bias $(\mathrm{LOA})$ of $-0.08(-0.86 ;+0.70) \mathrm{kPa}$ at the first and $-0.11(-0-83 ;+0.66)$ at the second sampling point (time point). At the following sampling points the agreement decreased to be only moderate. Additionally to the hypothesis of partially uncoupling the $\mathrm{PtcCO}_{2}$ from $\mathrm{PaCO}_{2}$ during spontaneous breathing, these findings rather support the hypothesis that procedural errors might be considerable reasons. The Vsign 2 sensor was fixed to earlobe, which was close to the surgical field. During surgery repetitive invasive access to the shoulder and its movement was often necessary to achieve good surgical conditions. These manoeuvres could have led to a more or less strong lateral inclination the head to the opposite side of surgery accompanied by mechanical disturbances of the ear sensor. Additionally, it cannot be completely excluded that irrigation solution, used during arthroscopic surgery diffused in the surrounding soft tissue. Both could have led to a swelling of subcutaneous and skin tissue with subsequently reduced tissue perfusion, resulting in increasing uncoupling the metabolism in peripheral tissue $\left(\mathrm{PtcCO}_{2}\right)$ from the central compartment $\left(\mathrm{PaCO}_{2}\right)$. Another reason for the only moderate agreement of $\mathrm{PtcCO}_{2}$ and $\mathrm{PaCO}_{2}$ might be the high rate of sensor disturbances by electro cautery, mechanical compression the sensor and by air lock on the sensor membrane. Although these disturbances lasted only briefly, their effect on the detection quality of the sensor may have been profound.

In addition to the $\mathrm{PtcCO}_{2}$ measurement the $\mathrm{V}$-sign 2 sensor detects partial oxygen saturation. In 20 patients with obstructive or restrictive lung disease needing long-term oxygen therapy Schafroth Törok and colleagues reported good agreement of $\mathrm{SpO}_{2}$ measured with a previous version of the Vsign 2 sensor and $\mathrm{SaO}_{2}$ [25]. In this investigation mean bias (LOA) of $\mathrm{SaO}_{2}$ and Vsign $\mathrm{SpO}_{2}$ was +1.2 (-0.3; $+2.7) \%$, which corresponds to a slight underestimation of the $\mathrm{SaO}_{2}$. However, the agreement was good.

In conclusion, regional anaesthesia combined with MAC led to mild and moderate hypercapnia without any significant disturbance the oxygenation in predominantly healthy patients undergoing shoulder surgery. Although, agreement between $\mathrm{PaCO}_{2}$ and $\mathrm{PtcCO}_{2}$ was only moderate in these spontaneous breathing patients, $\mathrm{PtcCO}_{2}$ monitoring significantly reduced incidence, degree and duration of hypercapnia.
Conflict of interest None.

\section{References}

1. Ghisi D, Fanelli A, Tosi M, Nuzzi M, Fanelli G. Monitored anesthesia care. Minerva Anestesiol. 2005;71:533-8.

2. Eberhard P, Mindt W, Schafer R. Cutaneous blood gas monitoring in the adult. Crit Care Med. 1981;9:702-5.

3. Storre JH, Steurer B, Kabitz HJ, Dreher M, Windisch W. Transcutaneous PCO2 monitoring during initiation of noninvasive ventilation. Chest. 2007;132:1810-6.

4. Hinkelbein J, Floss F, Denz C, Krieter H. Accuracy and precision of three different methods to determine $\mathrm{Pco} 2$ (Paco2 vs. Petco2 vs. Ptcco2) during interhospital ground transport of critically ill and ventilated adults. J Trauma. 2008;65:10-8.

5. Chhajed PN, Rajasekaran R, Kaegi B, Chhajed TP, Pflimlin E, Leuppi $\mathrm{J}$, et al. Measurement of combined oximetry and cutaneous capnography during flexible bronchoscopy. Eur Respir J. 2006;28:386-90.

6. Aittokallio J, Polo O, Hiissa J, Virkki A, Toikka J, Raitakari O, et al. Overnight variability in transcutaneous carbon dioxide predicts vascular impairment in women. Exp Physiol. 2008;93:880-91.

7. Aittokallio J, Saaresranta T, Virkki A, Karppinen N, Heinonen OJ, Aittokallio T, et al. Transcutaneous carbon dioxide profile during sleep reveals metabolic risk factors in post-menopausal females. Eur Respir J. 2009;34:1132-9.

8. Carter R, Banham SW. Use of transcutaneous oxygen and carbon dioxide tensions for assessing indices of gas exchange during exercise testing. Respir Med. 2000;94:350-5.

9. Rodriguez P, Lellouche F, Aboab J, Buisson CB, Brochard L. Transcutaneous arterial carbon dioxide pressure monitoring in critically ill adult patients. Intensive Care Med. 2006;32:309-12.

10. Baulig W, Schutt P, Roth HR, Hayoz J, Schmid ER. Clinical validation of a digital transcutaneous $\mathrm{PCO} 2 / \mathrm{SpO} 2$ ear sensor in adult patients after cardiac surgery. J Clin Monit Comput. 2007;21:303-9.

11. Lacerenza S, De Carolis MP, Fusco FP, La Torre G, Chiaradia G, Romagnoli C. An evaluation of a new combined Spo2/PtcCO2 sensor in very low birth weight infants. Anesth Analg. 2008;107:125-9.

12. Storre JH, Magnet FS, Dreher M, Windisch W. Transcutaneous monitoring as a replacement for arterial $\mathrm{PCO}(2)$ monitoring during nocturnal non-invasive ventilation. Respir Med. 2011;105:143-50.

13. Roediger R, Beck-Schimmer B, Theusinger OM, Rusch D, Seifert B, Spahn DR, et al. The revised digital transcutaneous $\mathrm{PCO} 2 / \mathrm{SpO} 2$ ear sensor is a reliable noninvasive monitoring tool in patients after cardiac surgery. J Cardiothorac Vasc Anesth. 2011;25:243-9.

14. American Society of Anesthesiologists (2007). ASA Standards GaS. http://www2.asahg.org/publications/p-106-asa-standards. guidelines-and-statements.aspx.

15. Chernik DA, Gillings D, Laine H, Hendler J, Silver JM, Davidson $\mathrm{AB}$, et al. Validity and reliability of the observer's assessment of alertness/sedation scale: study with intravenous midazolam. J Clin Psychopharmacol. 1990;10:244-51.

16. De Oliveira GS Jr, Ahmad S, Fitzgerald PC, McCarthy RJ. Detection of hypoventilation during deep sedation in patients undergoing ambulatory gynaecological hysteroscopy: a comparison between transcutaneous and nasal end-tidal carbon dioxide measurements. Br J Anaesth. 2010;104:774-8. 
17. Borgeat A, Dullenkopf A, Ekatodramis G, Nagy L. Evaluation of the lateral modified approach for continuous interscalene block after shoulder surgery. Anesthesiology. 2003;99:436-42.

18. Aldrete JA. The post-anesthesia recovery score revisited. J Clin Anesth. 1995;7:89-91.

19. Bland JM, Altman DG. Agreed statistics: measurement method comparison. Anesthesiology. 2012;116:182-5.

20. Kopka A, Wallace E, Reilly G, Binning A. Observational study of perioperative $\mathrm{PtcCO} 2$ and $\mathrm{SpO} 2$ in non-ventilated patients receiving epidural infusion or patient-controlled analgesia using a single earlobe monitor (TOSCA). Br J Anaesth. 2007;99: 567-71.

21. McCormack JG, Kelly KP, Wedgwood J, Lyon R. The effects of different analgesic regimens on transcutaneous $\mathrm{CO} 2$ after major surgery. Anaesthesia. 2008;63:814-21.
22. Chhajed PN, Miedinger D, Baty F, Bernasconi M, Heuss LT, Leuppi JD, et al. Comparison of combined oximetry and cutaneous capnography using a digital sensor with arterial blood gas analysis. Scand J Clin Lab Invest. 2010;70:60-4.

23. Delerme S, Montout V, Goulet H, Arhan A, Le Sache F, Devilliers $\mathrm{C}$, et al. Concordance between transcutaneous and arterial measurements of carbon dioxide in an ED. Am J Emerg Med. 2012;30:1872-6.

24. Fanelli G, Baciarello M, Squicciarini G, Malagutti G, Zasa M, Casati A. Transcutaneous carbon dioxide monitoring in spontaneously breathing, nonintubated patients in the early postoperative period. Minerva Anestesiol. 2008;74:375-80.

25. Schafroth Torok S, Leuppi JD, Baty F, Tamm M, Chhajed PN. Combined oximetry-cutaneous capnography in patients assessed for long-term oxygen therapy. Chest. 2008;133:1421-5. 